\title{
Fan Flow Deflection in Simulated Turbofan Exhaust
}

\author{
Dimitri Papamoschou* \\ University of California, Irvine, Irvine, California 92697-3975 \\ DOI: $10.2514 / 1.22552$
}

\begin{abstract}
Fan flow deflection for jet noise reduction was applied to subscale nozzles simulating the geometry and exhaust conditions of separate-flow turbofan engines. Two types of deflectors were tested, one comprising two pairs of vanes internal to the fan duct and the other consisting of a wedge positioned outside the fan duct. The noise reduction achieved by the vanes was strong in the downward direction and moderate in the sideline direction. The wedge generated significant attenuation in both directions. The acoustic results are consistent with the measured distortion of the mean velocity field. An approach for the treatment of nonaxisymmetric jets vis-à-vis perceived noise prediction is introduced.
\end{abstract}

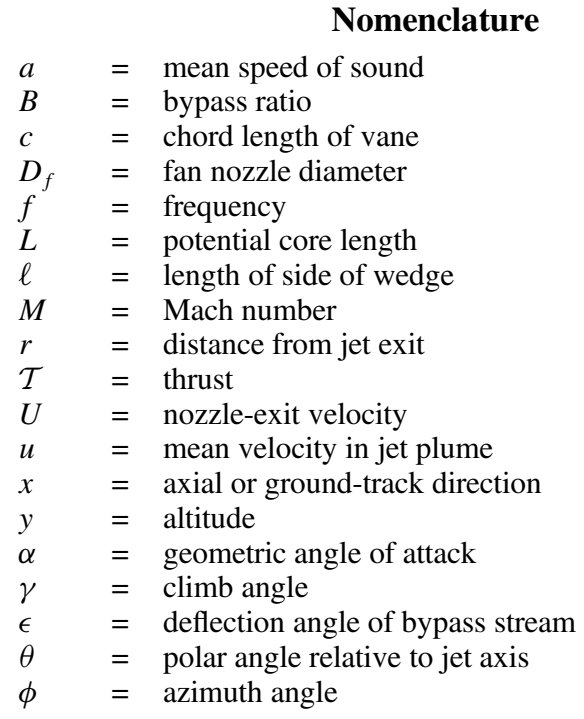

Subscripts

apex $=$ wedge apex relative to exit of fan nozzle

eng $=$ engine

$\exp =$ experiment

$p=$ primary (core) exhaust

$s \quad=$ secondary (fan) exhaust

sl $=$ sideline

te $\quad=$ trailing edge relative to exit of fan nozzle

$\infty=$ ambient

\section{Introduction}

$\mathbf{S}$ EVERAL years ago experiments at University of CaliforniaIrvine using eccentric dual-stream jets with a normal velocity profile showed considerable noise reduction in the direction of the thickened secondary (outer) flow [1]. The jets were high-speed, and the bypass ratios were small. Recently, the noise reduction trends observed in those experiments were verified in a larger rig at NASA Glenn Research Center [2]. Other researchers have independently

Presented as Paper 0993 at the AIAA 43rd Aerospace Sciences Meeting and Exhibit, Reno, NV, 10-13 January 2005; received 19 January 2006; revision received 14 May 2006; accepted for publication 15 May 2006. Copyright @ 2006 by D. Papamoschou. Published by the American Institute of Aeronautics and Astronautics, Inc., with permission. Copies of this paper may be made for personal or internal use, on condition that the copier pay the $\$ 10.00$ per-copy fee to the Copyright Clearance Center, Inc., 222 Rosewood Drive, Danvers, MA 01923; include the code $\$ 10.00$ in correspondence with the CCC.

*Professor. Associate Fellow AIAA observed similar benefits of offset coannular nozzles [3]. The concept of offset nozzle flows is an intriguing prospect for reducing turbulent mixing noise in high-bypass separate-flow turbofan engines used on commercial jetliners. Eccentric or severely offset nozzles are probably not viable because of the drastic redesign of the nacelle and the messy flow path in the outer nozzle. An alternative is to keep the exhaust coaxial but deflect the secondary (fan) flow using vanes or similar devices in the secondary flow path. Figure 1 provides a simplified view of this concept whereby the vertical lift of the vanes causes a downward deflection of the fan stream. Realistic applications would involve simultaneous downward and sideward deflections for suppression of noise underneath the aircraft and on the sideline. The method of fan flow deflection (FFD) has been tested in a variety of subscale experiments using coannular nozzles with simple flow lines [4,5]. The results appear promising both for low-bypass and high-bypass applications.

The physical mechanisms of noise reduction in offset jets are probably very complex and multifaceted. The experimental evidence so far indicates that, using offset nozzles or FFD, there is always a reduction of peak noise in the azimuthal direction of the maximum thickness of the fan flow. The peak noise is associated with sound generated by large-scale turbulent eddies [6]. For this reason, the main effect of offset nozzle flows is thought to be on the generation of noise from large-scale eddies. Mean velocity measurements indicate that the thickened secondary flow has the ability to reduce the convective Mach number of turbulent eddies near the end of the primary potential core, a region of intense turbulence activity, thereby curtailing the ability of these eddies to generate sound that reaches the far field in the direction of the thickened secondary flow [5]. This is a preliminary explanation of the phenomenon that addresses only one possible mechanism. Additional mechanisms may include reduction in the mean-flow gradients, reduction in the turbulent kinetic energy, and refraction of sound.

Importantly, the offset method also impacts another source of turbulent mixing noise, sound from fine-scale turbulence, in ways that are more unpredictable. Although this type of noise is weaker than sound from large-scale turbulence, it propagates in the lateral and upstream directions and can thus influence the perceived noise level. Eccentric nozzles invariably increase the fine-scale noise, as evidenced in past experiments $[1,2]$. Fan flow deflection can have a positive or negative effect depending on the details of the implementation. In fact, the choice of optimal deflectors will hinge on their ability to suppress large-scale noise as much as on their ability reduce, or not aggravate, fine-scale noise. For this reason, it is important to include in the acoustic evaluation metrics of community noise, such as the effective perceived noise level (EPNL), even if the experiment does not capture all the aspects of the engine environment.

Given the sensitivity of noise reduction on the details of the fan flow deflectors, it is essential to conduct experiments in nozzles that duplicate the complex exhaust flow passage of modern turbofan 


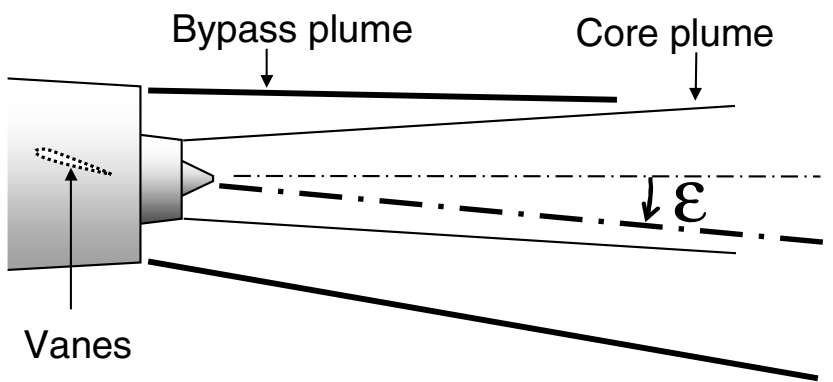

Fig. 1 General concept of fan flow deflection.

engines. This paper extends earlier work on FFD in simple nozzles to exhaust configurations with realistic flow lines. The investigation is initial, and the deflector arrangements have not been optimized. Acoustic results are accompanied by mean velocity measurements to gain some insight into the physics of noise suppression and the differences between the various deflector configurations.

\section{Experimental Setup}

\section{A. Nozzle}

The nozzle was a scaled-down version of the bypass ratio 5 baseline separate-flow nozzle used in heated air tests at NASA Glenn Research Center (GRC) [7], referred to as the "3BB" nozzle. The radial coordinates of the $3 \mathrm{BB}$ nozzle, obtained from GRC, were scaled down by a factor of 8 so that the nozzle mass flow rate would fit the flow capacity of our lab. Stereolithography files were generated, and the nozzle components were rapid prototyped from plastic (epoxy resin) material. Because this material becomes fragile for very small thickness, the relative thickness of the nozzle at the trailing edge is larger than that of the nozzle used in the GRC tests. The nozzle dimensions are listed in Table 1 . The coordinates will be shown later in the description of the deflectors.

The nozzle was attached to the dual-stream apparatus shown in Fig. 2. Mixtures of helium and air were delivered to the primary (core) and secondary (fan) nozzles. The helium mass fraction and the total pressure $p_{0}$ of each mixture were determined by the desired exit velocity and Mach number. For each stream, the individual mass flow rates of air and helium were calculated based on the helium mass fraction and the total pressure. Corresponding to the mass flow rate of air is the total pressure of the air flow alone $p_{0_{\text {air }}}$. The helium mass fraction was set by first running air alone through the nozzle to match $p_{0_{\text {air }}}$, then adding helium to match $p_{0}$. This is the same procedure used by Doty and McLaughlin [8] in their single-stream helium-air mixture jets. The total pressures were held to within $0.5 \%$ of the target values, resulting in errors of $0.3 \%$ in the velocity and $0.2 \%$ in the Mach number.

Two types of investigations were conducted: acoustic surveys and mean velocity surveys. For the acoustic tests, helium-air mixtures were used in the core and fan streams to match the typical exit conditions of a separate-flow turbofan engine with bypass ratio 4.8 at

Table 1 Exit flow conditions

\begin{tabular}{lcc}
\hline \hline Quantity & Core & Fan \\
\hline Nozzle diameter (mm) & 17.0 & 31.0 \\
Plug diameter (mm) & 11.5 & -3.1 \\
Height of exit annulus (mm) & 2.2 & 0.8 \\
Lip thickness (mm) & 0.8 & $334 \mathrm{~m} / \mathrm{s}$ \\
Velocity $^{\mathrm{a}}$ & $460 \mathrm{~m} / \mathrm{s}$ & 0.95 \\
Mach number $^{\mathrm{a}}$ & 0.86 & 4.8 \\
Bypass ratio $^{\mathrm{a}}$ & - & $220 \mathrm{~m} / \mathrm{s}$ \\
Velocity $^{\mathrm{b}}$ & $310 \mathrm{~m} / \mathrm{s}$ & 0.66 \\
Mach number $^{\mathrm{b}}$ & 1.00 & 1.9 \\
Bypass ratio $^{\mathrm{b}}$ & - & \\
\hline \hline
\end{tabular}

${ }^{\mathrm{a} A c o u s t i c ~ i n v e s t i g a t i o n . ~}$

${ }^{b}$ Mean-flow investigation.

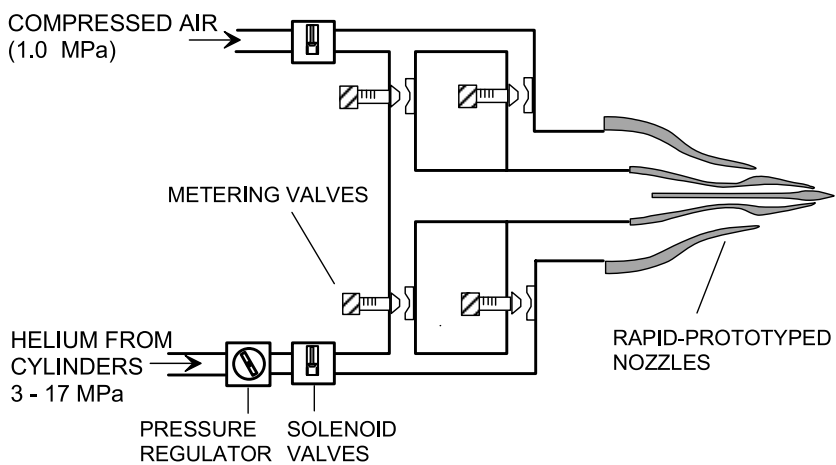

Fig. 2 Dual-stream jet apparatus.

takeoff power. The Reynolds number of the jet, based on fan diameter, was $6 \times 10^{5}$. The mean-flow surveys required long run times for which use of helium-air mixtures would have been prohibitively expensive. These tests used pure air in both the fan and core streams and so the velocity magnitudes are not realistic. However, the velocity ratio $\left(U_{s} / U_{p}=0.7\right)$ matched that in the acoustic tests; hence, some fundamental fluid mechanics of mixing were preserved.

\section{B. Deflectors}

The deflectors covered in this paper reflect an initial nonoptimized investigation of FFD in realistic nozzles. Two types of deflectors were tested: one comprising two pairs of vanes internal to the fan duct $(4 \mathrm{~V})$ and the other consisting of a wedge external to the fan $\operatorname{duct}\left(W_{e}\right)$. The vane arrangement is similar to one of the promising configurations tested previously in a conventional coaxial nozzle [5]. Table 2 describes the two configurations, and Figs. 3 and 4 plot the respective geometries. The vanes were fabricated from a $0.13-\mathrm{mm}$ brass sheet and were attached to the outer surface of the inner nozzle with adhesive. Electrical tape (0.18-mm thick) was wrapped around the vanes to produce a round leading edge. The Mach numbers at the leading and trailing edges were estimated to be 0.4 and 0.7 , respectively. The wedge-type deflector was a triangle cut from 3.5mm-thick nylon sheet. The thickness of the wedge, $3.5 \mathrm{~mm}$, was larger than the fan exit height $(3.1 \mathrm{~mm})$. It is evident from the diagrams of Figs. 3 and 4 that the $4 \mathrm{~V}$ deflector is supposed to impart a mostly downward deflection of the bypass plume, whereas the $W_{e}$ deflector is expected to induce azimuthal motions that force the plume sideward (symmetrically around the vertical plane) and downward. The fluid mechanics of the deflectors will be discussed in section III.B. Based on a recent computational study of the aerodynamics of internal vane deflectors [9], the static-thrust loss of case $4 \mathrm{~V}$ is expected to be around $0.2 \%$. No aerodynamic data exist yet for the wedge flow.

\section{Noise Measurement}

Noise measurements were conducted inside an anechoic chamber using a 3.2-mm condenser microphone (Brüel \& Kjær 4138) with frequency response of $140 \mathrm{kHz}$. Figure 5 shows the layout. The microphone was mounted on a pivot arm and traced a circular arc centered at the jet exit with a radius of $r=0.96 \mathrm{~m}$. The polar angle $\theta$ ranged from 20 to $120 \mathrm{deg}$ in intervals of $5 \mathrm{deg}$ for $20 \leq \theta \leq 50 \mathrm{deg}$ and $10 \mathrm{deg}$ for the rest. Rotation of the nozzle assembly allowed variation of the azimuth angle from $\phi=0$ to $90 \mathrm{deg}$ in increments of $30 \mathrm{deg}$. The microphone was sampled at $400 \mathrm{kHz}$ by a fast analog-to-

Table 2 Deflector configurations

\begin{tabular}{|c|c|}
\hline Case & Configuration \\
\hline Base & Clean nozzle \\
\hline $4 \mathrm{~V}$ & $\begin{array}{l}\text { Two pairs of vanes at } \phi_{1}=70 \mathrm{deg} \text { and } \phi_{2}=110 \mathrm{deg} \\
\alpha_{1}=15 \mathrm{deg}, \alpha_{2}=10 \mathrm{deg}, c=4 \mathrm{~mm}, x_{\mathrm{te}}=-1 \mathrm{~mm}\end{array}$ \\
\hline$W_{e}$ & External wedge with $x_{\text {apex }}=0 \mathrm{~mm}, \alpha=18 \mathrm{deg}, \ell=10 \mathrm{~mm}$. \\
\hline
\end{tabular}




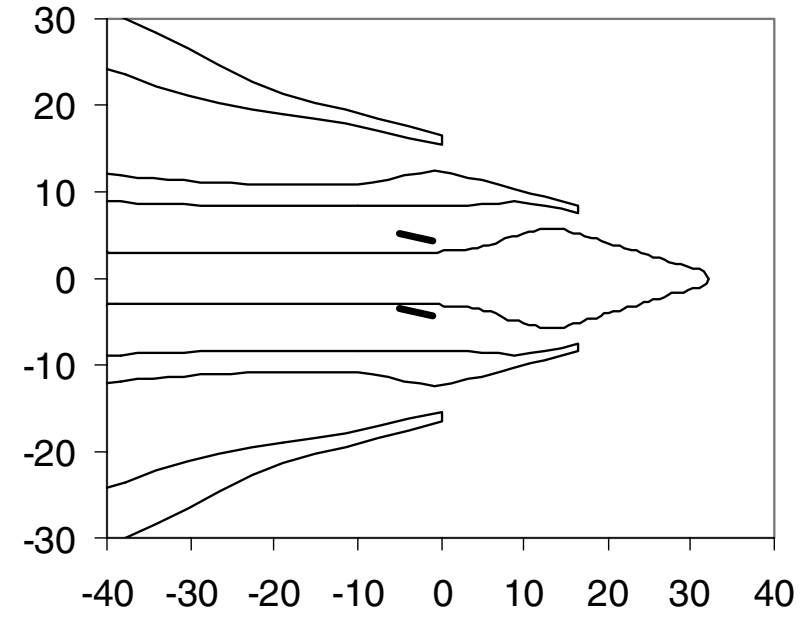

Side view

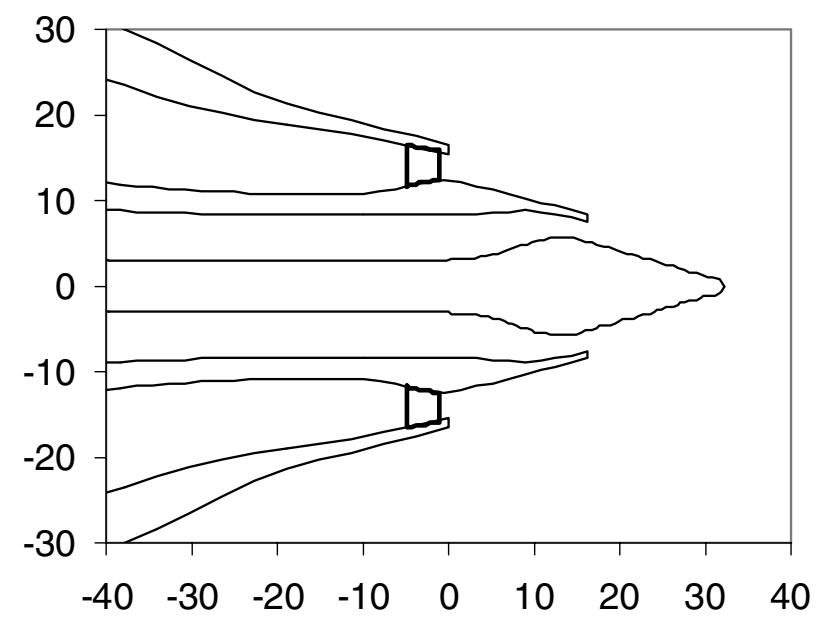

Top view

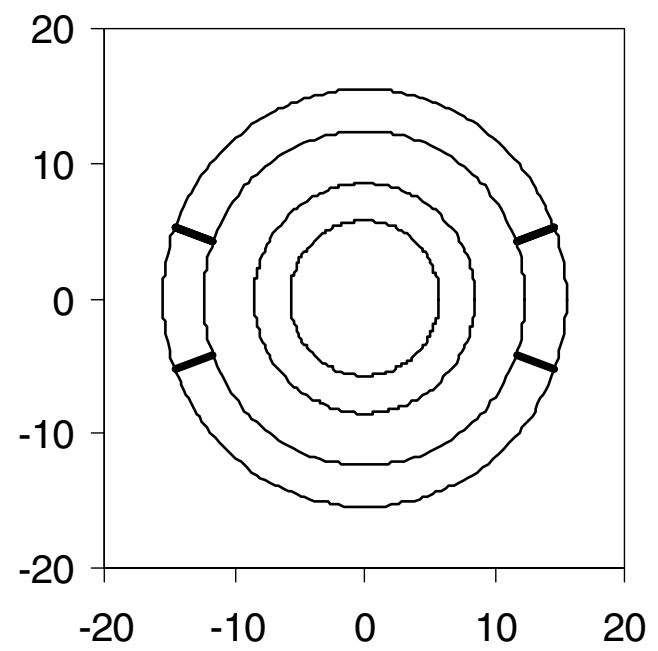

End view

Fig. 3 Deflector configuration with two pairs of vanes $(4 \mathrm{~V})$.

digital board (National Instruments PCI-6070E) installed in a Pentium 4 computer. Each recording consisted of 54,280 samples (135 ms), corresponding to the passage of about 10,000 eddies the size of the inner-jet diameter. The signal was high-pass filtered at $500 \mathrm{~Hz}$ by a Butterworth filter to remove spurious low-frequency noise. The narrowband power spectrum of the microphone voltage was computed using a 2048-point fast Fourier transform providing a
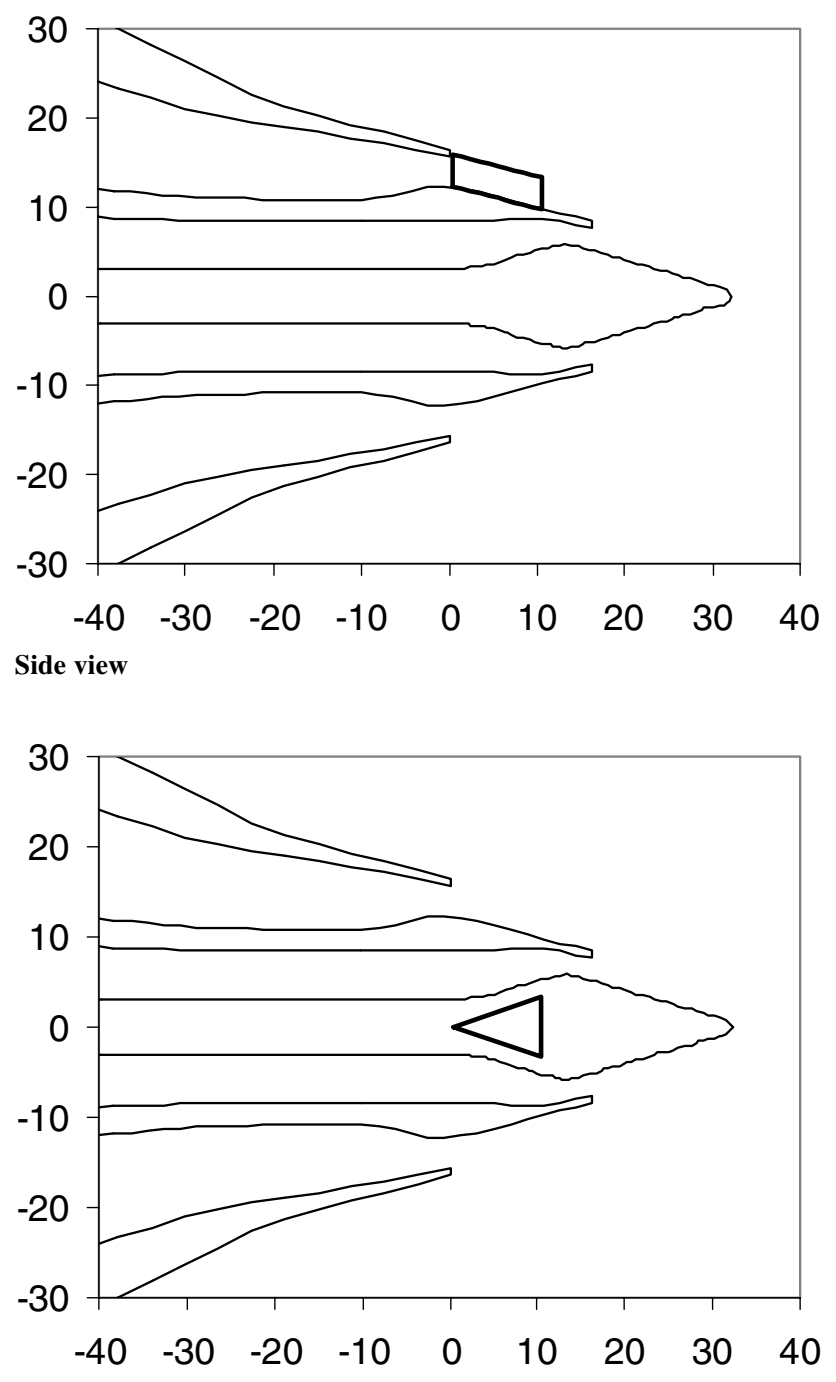

Top view

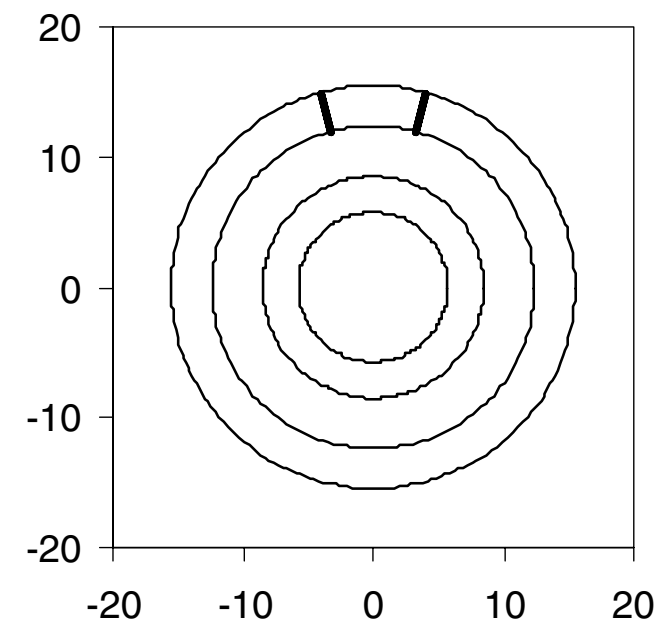

End view

Fig. 4 Deflector configuration with external wedge $\left(W_{e}\right)$.

spectral resolution of $195 \mathrm{~Hz}$. Each sound spectrum was corrected for the microphone frequency response, free field response, and atmospheric absorption. Integration of the corrected (lossless) spectrum yielded the overall sound pressure level (OASPL). Repetition of an experiment under varying temperature and relativehumidity conditions (typically from 20 to 50\%) yields spectra that 


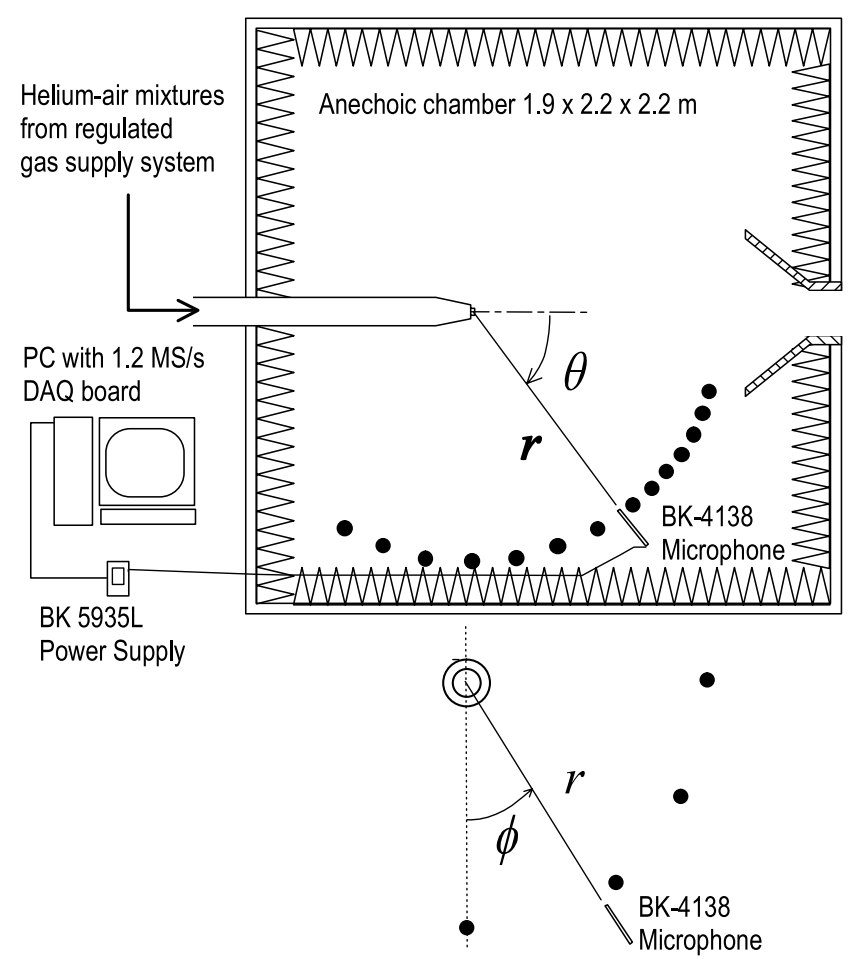

Fig. 5 Jet aeroacoustics facility.

differ by at most $0.5 \mathrm{~dB}$. Comparison of the acoustics of our coaxial helium-air mixture jets with the acoustics of similar large-scale heated jets shows excellent agreement in all measures of noise: spectral shapes, spectral levels, and overall sound pressure levels [10].

In assessing the acoustic merits of each configuration, it is important to include metrics of community noise, namely the perceived noise level (PNL). To resolve the full-scale audible spectrum pertinent to the PNL, the sound spectra were extrapolated to frequencies higher than those resolved in the experiment $(140 \mathrm{kHz})$ using a decay slope of $-30 \mathrm{~dB} /$ decade. This highfrequency roll off is consistently observed in spectra of large-scale and fine-scale turbulence noise of high-speed jets with a variety of nozzle shapes, as studied by Tam [11]. The PNL results are fairly insensitive on the assumed roll-off slope, and even an assumed slope of zero will yield an EPNL difference increase of no more than $0.2 \mathrm{~dB}$. The reason is that sound at high frequency is damped very rapidly by atmospheric absorption. To scale up the results, the laboratory frequency was divided by the scale factor $\sqrt{\mathcal{T}_{\text {eng }} / \mathcal{T}_{\text {exp }}}$.

Earlier papers have described the conversion of spectra to EPNL measured by the takeoff monitor, a location directly underneath the flight path [5]. Because the sound emitted by the jets of this study has strong azimuthal dependence, the prediction of sideline EPNL is much more elaborate. Outlined here are procedures for assessing sideline EPNL for sound fields that are not necessarily axisymmetric. This is relevant for processing the current data and for providing guidance to future studies of nonaxisymmetric jets.

Figure 6 shows the flight paths considered. The flyover path is straight and level at an altitude of $460 \mathrm{~m}$. To conform with flyover EPNL calculations of previous investigations [7], the angle of attack of the engine axis was set to $\alpha=0$ deg. However, given the strong polar directivity of jet noise, consideration of a realistic flyover angle of attack ( $\alpha \sim 10 \mathrm{deg}$ ) would be advisable as a future standard in predicting EPNL from laboratory tests. For the sideline noise, the flight path comprises a horizontal takeoff roll followed immediately by a straight climb at angle $\gamma=15 \mathrm{deg}$ and $\alpha=10 \mathrm{deg}$. The sideline noise is monitored on a line parallel to the runway centerline and offset by $450 \mathrm{~m}$. Letting $x_{\mathrm{sl}}$ denote the distance along the sideline, measured from the liftoff point, the sideline EPNL first rises then falls with increasing $x_{\mathrm{sl}}$. The maximum level, found here iteratively, is the one used in certification. For both flyover and sideline predictions the aircraft velocity is $100 \mathrm{~m} / \mathrm{s}\left(M_{\infty}=0.28\right)$.

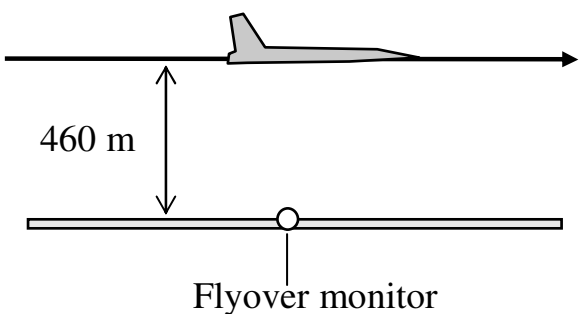

a)

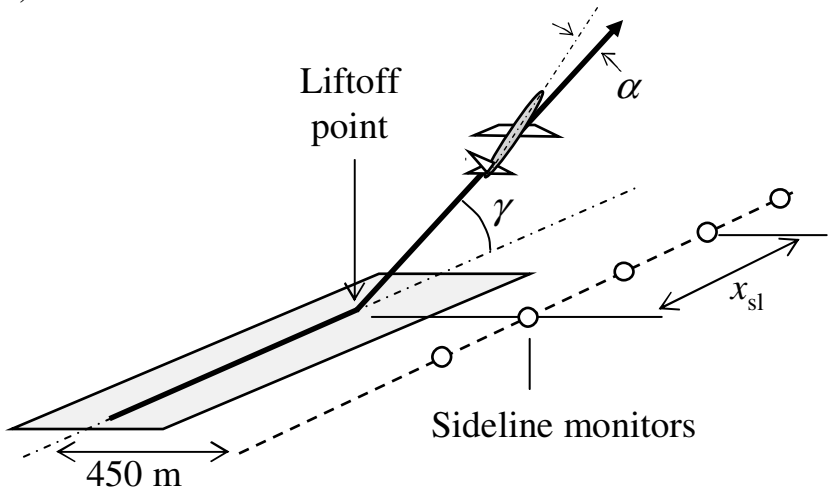

b)

Fig. 6 Monitoring locations and flight paths for PNL evaluation: a) flyover; b) sideline.

We now construct geometric relations for the observation distance and angles of the jet exhaust from an arbitrary point on the ground. Figure 7 shows the geometric constructions. Using the Cartesian coordinate system $(x, y, z)$, the airplane's actual position is $\left(x^{\prime}, y^{\prime}, 0\right)$,
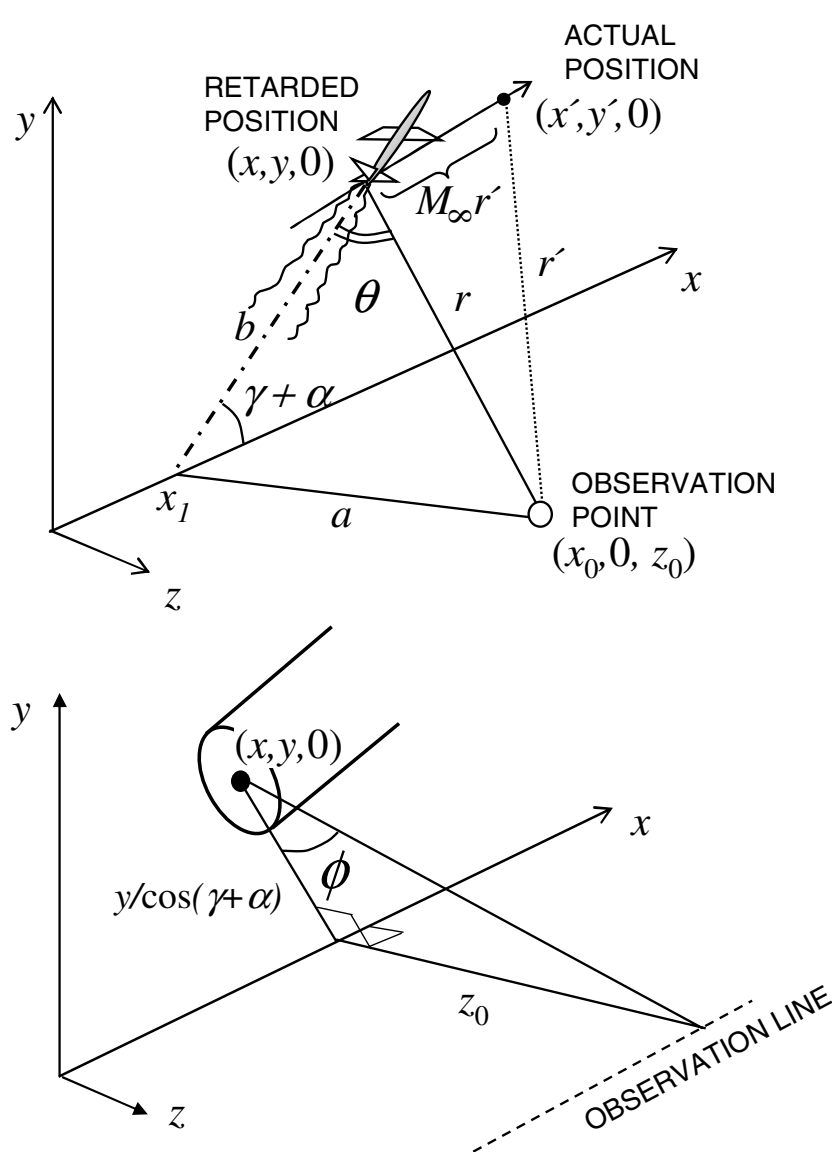

Fig. 7 Geometric construction for observation distance $r$ and angles $\theta$ and $\phi$. 
its retarded position is $(x, y, 0)$, and the observation point is at $\left(x_{0}, 0, z_{0}\right)$. The actual distance of the observer from the airplane is

$$
r^{\prime}=\sqrt{\left(x^{\prime}-x_{0}\right)^{2}+y^{\prime 2}+z_{0}^{2}}
$$

It can be shown easily that the retarded position is at a distance $M_{\infty} r^{\prime}$ along the flight path behind the actual position. The observation distance to the retarded position is

$$
r=\sqrt{\left(x-x_{0}\right)^{2}+y^{2}+z_{0}^{2}}
$$

Assuming that the axis of the jet exhaust is aligned with the longitudinal axis of the airplane, the angle of the jet axis with respect to the horizontal is $\gamma+\alpha$. The jet axis intercepts the ground at $\left(x_{1}, 0,0\right)$, where

$$
x_{1}=x-\frac{y}{\tan (\gamma+\alpha)}
$$

From the geometry of the top diagram of Fig. 7, the polar observation angle is

$$
\tan (\theta / 2)=\sqrt{\frac{(p-b)(p-r)}{p(p-a)}}
$$

where

$$
\begin{gathered}
a=\sqrt{\left(x_{0}-x_{1}\right)^{2}+z_{0}^{2}} \\
b=\frac{y}{\sin (\gamma+\alpha)} \\
p=\frac{1}{2}(a+b+r)
\end{gathered}
$$

Referring to the lower diagram of Fig. 7, the azimuth observation angle is

$$
\tan (\phi)=\frac{z_{0}}{y} \cos (\gamma+\alpha)
$$

Figure 8 plots the relation between azimuth and polar angles observed from various positions along the sideline. Flight parameters are $\gamma=15 \mathrm{deg}$ and $\alpha=10 \mathrm{deg}$. The maximum EPNL is found to occur for $500<x_{\mathrm{sl}}<1000 \mathrm{~m}$. This gives us clues as to which combinations of $\theta$ and $\phi$ are relevant to sideline EPNL. For example, in the polar direction of peak sound emission $(\theta \sim 30 \mathrm{deg})$ azimuth

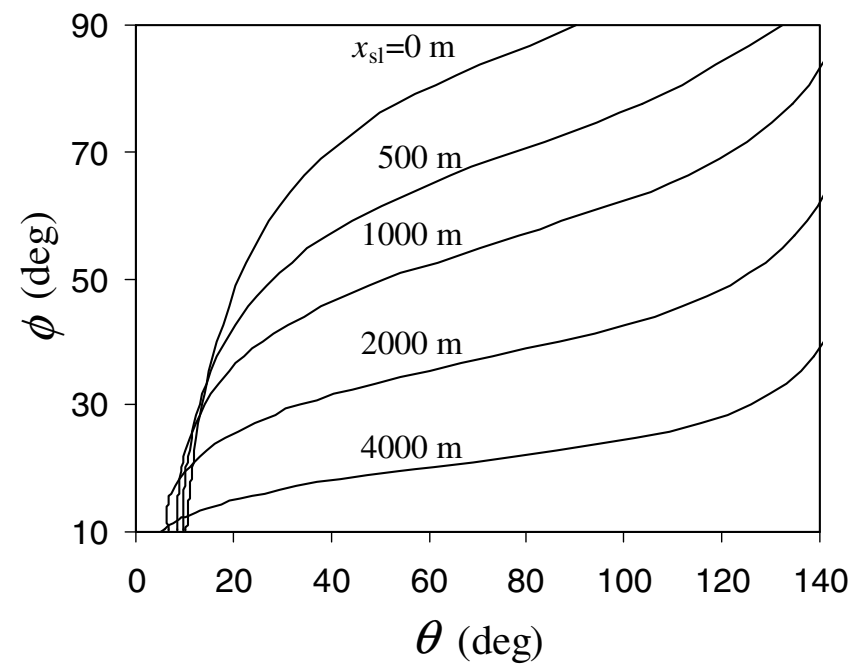

Fig. 8 Relation between polar and azimuth observation angles for various locations along sideline. angles near $45 \mathrm{deg}$ are important. At $\theta=90 \mathrm{deg}$ the relevant azimuthal angle is $\phi \sim 60 \mathrm{deg}$.

The computation of EPNL is based on engine thrust $\mathcal{T}_{\text {eng }}=$ $225 \mathrm{kN}$ (scale factor of 70) and involves the following steps:

1) The aircraft position is computed every 0.5 -s interval. For each observation time $t$, the distance $r(t)$, polar emission angle $\theta(t)$, and azimuth emission angle $\phi(t)$ are computed from Eqs. (1-4).

2) For each $t$, the lossless scaled-up spectrum corresponding to $\theta(t)$ and $\phi(t)$ is obtained. This step requires interpolation between spectra and, for polar angles outside the range covered in the experiment, moderate extrapolation. To enhance the accuracy of interpolation or extrapolation, the spectra were smoothed using a Savitzky-Golay filter [12] that removes extraneous wiggles but preserves the basic shape of the spectrum.

3) The spectrum is Doppler shifted to account for the motion of the aircraft. The relations of McGowan and Larson [13] are used:

$$
\frac{f_{\text {flight }}}{f_{\text {static }}}=\frac{1+\left(M_{c}-M_{\infty}\right) \cos \theta}{1+M_{c} \cos \theta}
$$

The convective Mach number $M_{c}$ is obtained from the empirical relations of Murakami and Papamoschou [14].

4) The spectrum is corrected for distance and atmospheric absorption. The distance correction is

$$
-20 \log _{10}\left[\frac{\left(r / D_{f}\right)_{\mathrm{eng}}}{\left(r / D_{f}\right)_{\exp }}\right]
$$

The absorption correction is applied for $29^{\circ} \mathrm{C}$ ambient temperature and $70 \%$ relative humidity (conditions of least absorption) using the relations of Bass et al. [15].

5) The spectrum is discretized into $1 / 3$-octave bands, and the PNL is computed according to Part 36 of the Federal Aviation Regulations [16].

6) The PNL is corrected for lateral attenuation according to SAE AIR 1571 [17]. This applies to only the sideline estimate.

7) The above steps result in the time history of perceived noise level, PNL $(t)$. From it, the maximum level of PNL (PNLM) is determined. The duration of PNL exceeding PNLM $10 \mathrm{~dB}$ is calculated, and the corresponding "duration correction" is computed according to FAR 36. The EPNL equals PNLM plus the duration correction. This estimate of EPNL does not include the "tone correction," a penalty for excessively protrusive tones in the $1 / 3$ octave spectrum that are absent from our spectra anyway. In presenting the $\operatorname{PNL}(t)$ results, the time origin is defined as follows: For the flyover, $t=0$ corresponds to the passage of the aircraft directly over the observer. For the sideline, $t=0$ is the time at liftoff.

The EPNL estimate is used here as a means to integrate all the acoustic features into a preliminary assessment of community noise and thus a preliminary "figure of merit" for each configuration. The estimate does not include factors such as aerodynamic effects of forward flight, installation effects, and noise from sources other than turbulent mixing noise (e.g., fan tones, airframe sound) that affect the EPNL of a real airplane.

\section{Mean Velocity Measurement}

A Pitot rake, shown in Fig. 9, was used to survey the total pressure in the jet plume. The rake consisted of five stainless steel tubes, each 70-mm long, supported by an airfoil-shaped holder. The tubes were mounted $10.2 \mathrm{~mm}$ apart, and their inner diameter was $1.0 \mathrm{~mm}$. The rake was mounted on a carriage with motorized motion in the $y$ direction and manual positioning in the $x$ and $z$ directions. The probe second from the top is the reference probe, initially positioned at the tip of the plug. The negative $y$ direction defines the direction of the ground $(\phi=0)$.

The five probes of the rake were connected individually to five pressure transducers (Setra Model 207). The transducers were mounted on the traverse assembly to minimize the length of the tubing from the probe to the transducer. This arrangement minimized the response time of the probe-transducer system to values low enough to resolve the sharp spatial gradients in total pressure near the 


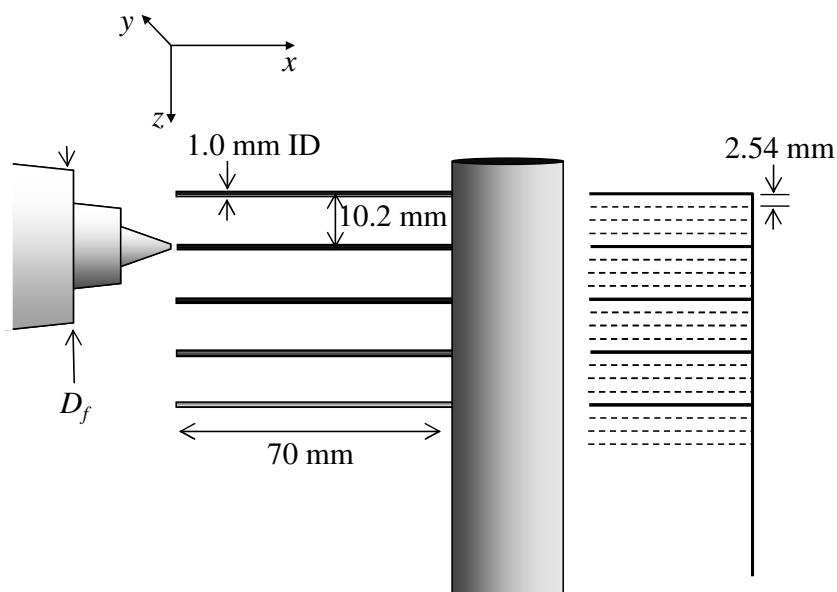

Fig. 9 Pitot probe rake. Diagram on the right shows the rake's $z$ positioning.

nozzle exit. The typical carriage speed was $10 \mathrm{~mm} / \mathrm{s}$ and the transducers were sampled each at 1000 samples per second by an analog-to-digital board. Each $y$ traverse resulted in 8000 samples. Mach number and velocity were computed from the pitot pressure assuming constant total temperature (equal to the ambient temperature) and uniform static pressure.

For each axial location the rake traversed the plume in the $y$ direction a total of four times. Each time, the rake was moved by a $z$ increment of $2.54 \mathrm{~mm}$, i.e., one-fourth of the probe spacing. This resulted in $20 \mathrm{z}$ locations being surveyed for each $x$. The survey resolution was $2.5 \mathrm{~mm}$ in $z$ and $1.0 \mathrm{~mm}$ in $y$. A total of $25 x$ locations were surveyed for each case, with $x / D_{f}$ ranging from 0 to 10 . The surveys assumed symmetry of the velocity field around the plane $z=0$. Therefore, the surveys resolved the region $z \geq 0$ and a small portion of the region $z<0$ near $z=0$. Velocity data from the latter region were used to determine the true plane of symmetry of $u$, which may differ slightly from the geometric plane $z=0$. The true plane of symmetry was then used to make a mirror image of the velocity data.

\section{Results and Discussion}

\section{A. Acoustics}

Figure 10 compares the far-field sound pressure level spectra of case $4 \mathrm{~V}$ with the baseline for a variety of polar angles and for microphone azimuth angles of 0 and $60 \mathrm{deg}$. At $\theta=20 \mathrm{deg}$ we note a deep reduction in the downward sound emission, as much as $17 \mathrm{~dB}$ at $f \sim 10 \mathrm{kHz}$. This is consistent with the main attribute of FFD to reduce noise from large-scale turbulent eddies, which radiate at polar angles near the jet axis. Reduction in the sideline noise is moderate, approximately $5 \mathrm{~dB}$ at $f \sim 10 \mathrm{kHz}$, and a crossover occurs for $f>30 \mathrm{kHz}$. As the polar angle increases, the downward noise reduction remains substantial up to about $\theta=60 \mathrm{deg}$, whereas the sideline reduction fades away for $\theta>40 \mathrm{deg}$. At $\theta=90 \mathrm{deg}$ the spectra of $4 \mathrm{~V}$ practically coincide with those of the baseline jet. At higher polar angles, there is a moderate noise increase at medium frequencies for $\phi=0 \mathrm{deg}$ but no significant increase for $\phi=60$ deg.

The OASPL directivity of $4 \mathrm{~V}$ is shown in Fig. 11 for all the azimuth angles surveyed. At $\theta=20 \mathrm{deg}$ there is a large reduction of the downward OASPL of around $9 \mathrm{~dB}$, consistent with the corresponding spectral decrease in Fig. 10. The peak level of downward OASPL drops by $6.5 \mathrm{~dB}$. Significant reduction in downward OASPL occurs for $\theta<50 \mathrm{deg}$ followed by a small increase in OASPL, around $2 \mathrm{~dB}$, for $\theta>70 \mathrm{deg}$. The effect of increasing azimuth angle is to progressively lessen both the decrease in peak OASPL and the increase in lateral OASPL. The increase in lateral OASPL at large polar angles could be due to the enhanced velocity gradients in the radial direction, and ensuing increased turbulent kinetic energy, at the top of the jet.
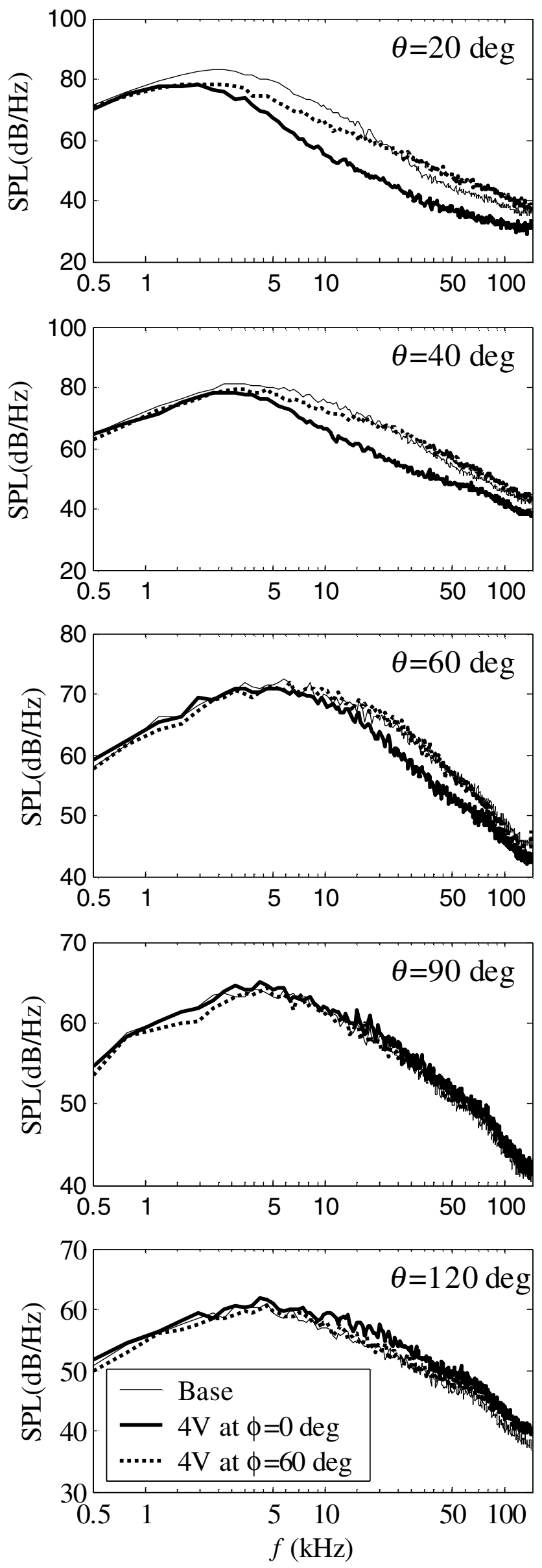

Fig. 10 Far-field sound pressure level (SPL) spectra for case $4 \mathrm{~V}$. 


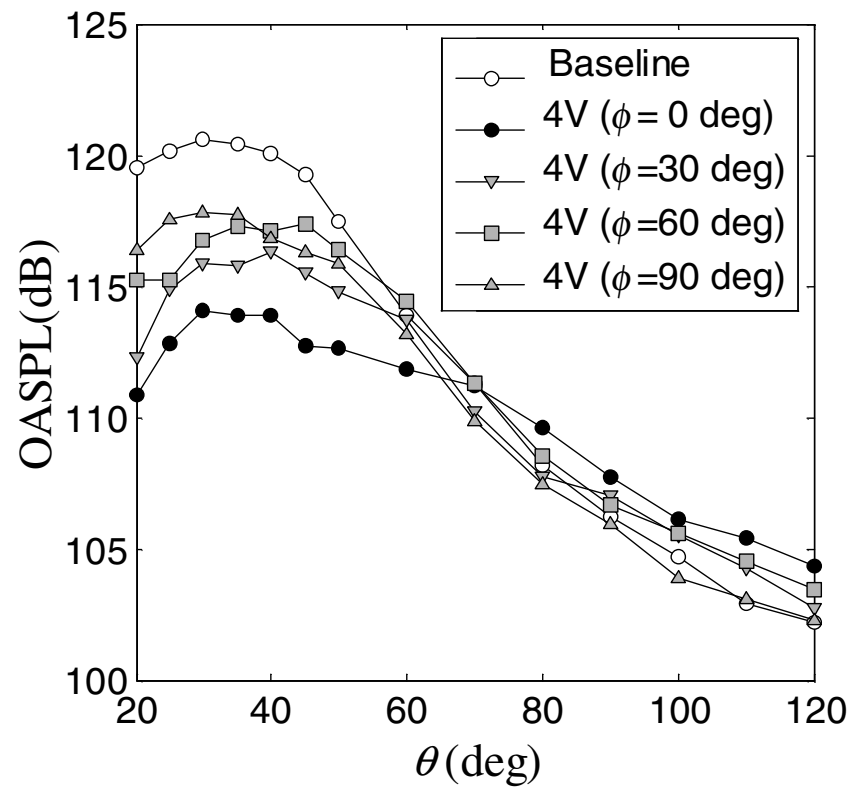

Fig. 11 Directivity of OASPL for case $4 \mathrm{~V}$ at various microphone azimuth angles.

Figure 12 plots the PNL time histories of $4 \mathrm{~V}$ for the flyover and sideline observation stations (flight paths of Figs. $6 a$ and $6 \mathrm{~b}$, respectively). Times on the left side of the peak correspond to large polar angles, and times on the right side of the peak correspond to shallow polar angles. The flyover plot captures the large spectral

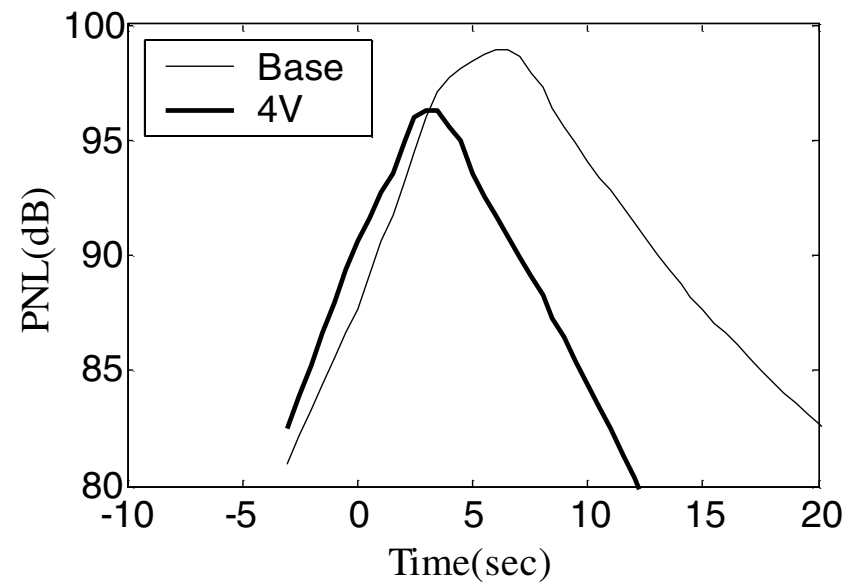

a)

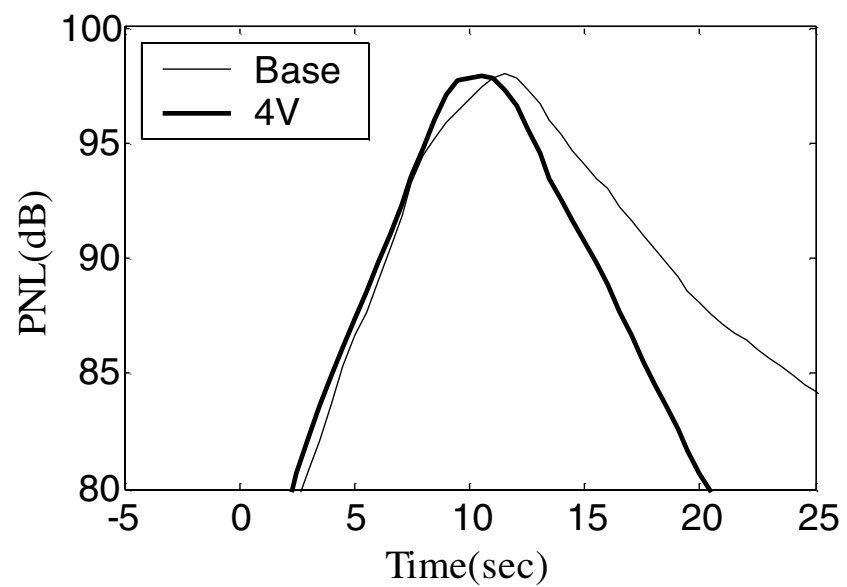

b)

Fig. 12 PNL history for case 4V: a) flyover; b) sideline at maximum EPNL. reductions at small $\theta$ and the moderate noise increase for large $\theta$. There are reductions in both the peak level of PNL and the duration of the 10-dB down level, resulting in an EPNL reduction of $4.0 \mathrm{~dB}$. The sideline PNL time history reflects the moderate noise reduction at shallow polar angles and the lack of change for large polar angles. The peak level is basically unchanged, and the benefit comes from the reduced time duration of the $10-\mathrm{dB}$ down level. The sideline EPNL is reduced by $1.0 \mathrm{~dB}$. In summary, this particular vane configuration is very effective in reducing the perceived noise level directly underneath the aircraft but yields modest reduction in the sideline perceived noise level.

We now examine the acoustics of the external wedge deflector, case $W_{e}$. Figure 13 plots the far-field sound pressure level spectra for various polar angles and for azimuth angles $\phi=0$ and $60 \mathrm{deg}$. We note some important differences from the corresponding spectra of case $4 \mathrm{~V}$ (Fig. 10). Case $W_{e}$ gives more moderate spectral reductions, but they are practically the same at $\phi=0$ and $60 \mathrm{deg}$. There are no significant crossovers, and unlike $4 \mathrm{~V}$, the spectral levels at large polar angles do not show any noticeable increase. The results of Fig. 13 indicate that the wedge-shaped deflector yields a noise reduction that is more uniformly distributed in polar and azimuth angles.

The above observation is also reflected in the OASPL directivity plotted in Fig. 14. There are appreciable OASPL reductions for polar angles up to $\theta=80 \mathrm{deg}$, with small reductions persisting up to $\theta=110 \mathrm{deg}$. In the downward direction, the peak OASPL drops by $4 \mathrm{~dB}$. The OASPL reduction does not change much as the azimuth angle increases from $\phi=0$ to $60 \mathrm{deg}$. At $\phi=90 \mathrm{deg}$ we observe a small increase in the OASPL levels, but they are well below the baseline levels for $\theta<80 \mathrm{deg}$.

The PNL time histories of case $W_{e}$, plotted in Fig. 15, show the effectiveness of this configuration in reducing flyover and sideline noise by roughly the same amount. The reduction comes mainly from the drop in the peak level of PNL. The 10-dB down duration factor is slightly worse for $W_{e}$ than for the baseline. The EPNL reductions are $4.0 \mathrm{~dB}$ for flyover and $3.8 \mathrm{~dB}$ for sideline. A possible practical implementation of the external wedge deflector could involve passive or active reshaping of the pylon supporting the engine.

\section{B. Mean Flow}

The mean-flow results are presented in the form of isocontours of $u / U_{p}$ on various planes. The coordinate system is illustrated in Fig. 9, with negative $y$ indicating the direction of the ground. The surveys start at the tip of the plug that is located at $x / D_{f}=1.0$, with $x=0$ defining the exit plane of the fan nozzle. Figure 16 shows the velocity isocontours on the plane $z=0$ for the three cases investigated. Jet $4 \mathrm{~V}$ experiences a significant downward deflection. Based on the shift of the $u / U_{p}=0.2$ contour from the baseline at $x / D_{f}=10$, the deflection angle is $\epsilon \approx 3 \mathrm{deg}$. We observe a significant reduction in the length of the primary potential core, defined here as the area enclosed by the $u / U_{p}=0.9$ contour, from $L_{p} / D_{f}=5.1$ for the baseline to $L_{p} / D_{f}=4.0$ for case $4 \mathrm{~V}$. It is apparent that the vanes of case $4 \mathrm{~V}$ produce the dual effect of concentrating low-speed flow on the underside of the jet and enhancing mixing that shortens the primary potential core. The changes in the velocity isocontours of jet $W_{e}$ are more subtle. The overall deflection of the flow is very small. There is some asymmetry around the $x$ axis, but from this view, it appears weak relative to that of the $4 \mathrm{~V}$ jet. The length of the primary potential core is reduced slightly from $L_{p} / D_{f}=5.1$ to 4.8 . The velocity defect caused by the wedge is evident on the upper contours up to $x / D_{f}=2.0$. From this preliminary observation, and given the size of the wedge used, we infer that the length of the recirculation region is roughly 10 times the base of the wedge, whereas this ratio is around 3 for a fully immersed wedge of similar angle [18]. It is expected, therefore, that the drag of the $W_{e}$ wedge, whose base is open to the ambient pressure, is much less that the drag of a fully immersed wedge.

An axial station of interest regarding noise emission from largescale structures is the end of the primary potential core. Phased array measurements indicate that the strongest noise sources are 

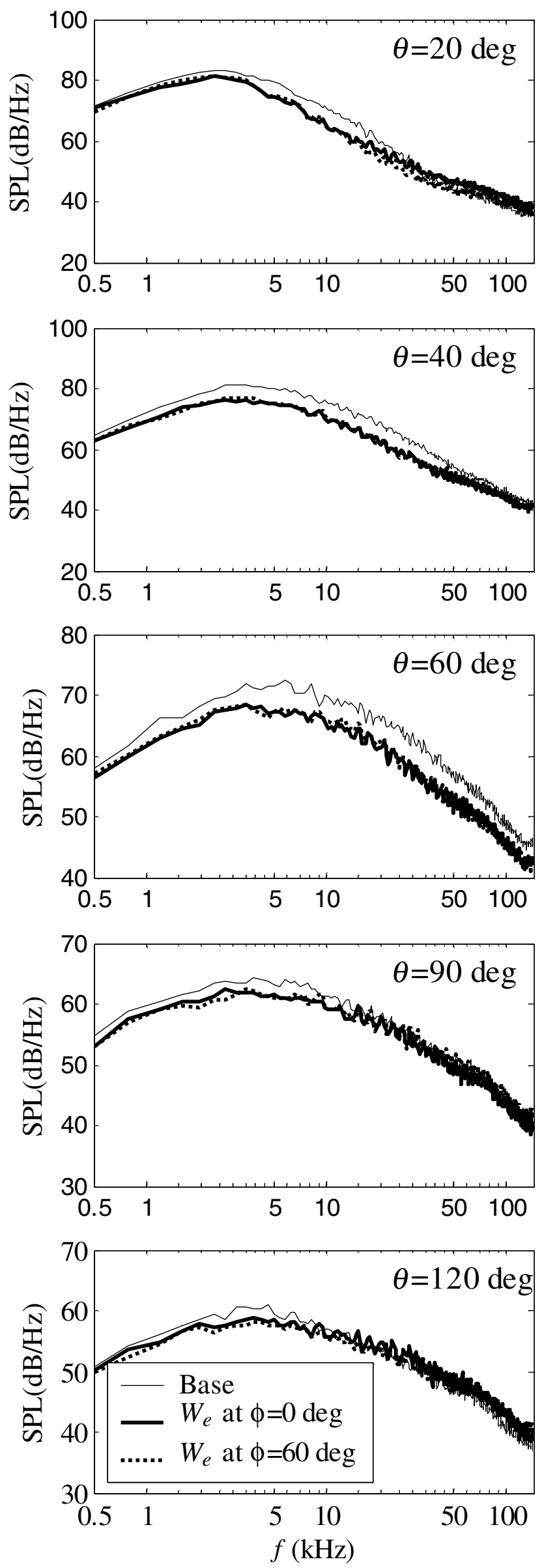

Fig. 13 Far-field SPL spectra for case $W_{e}$.

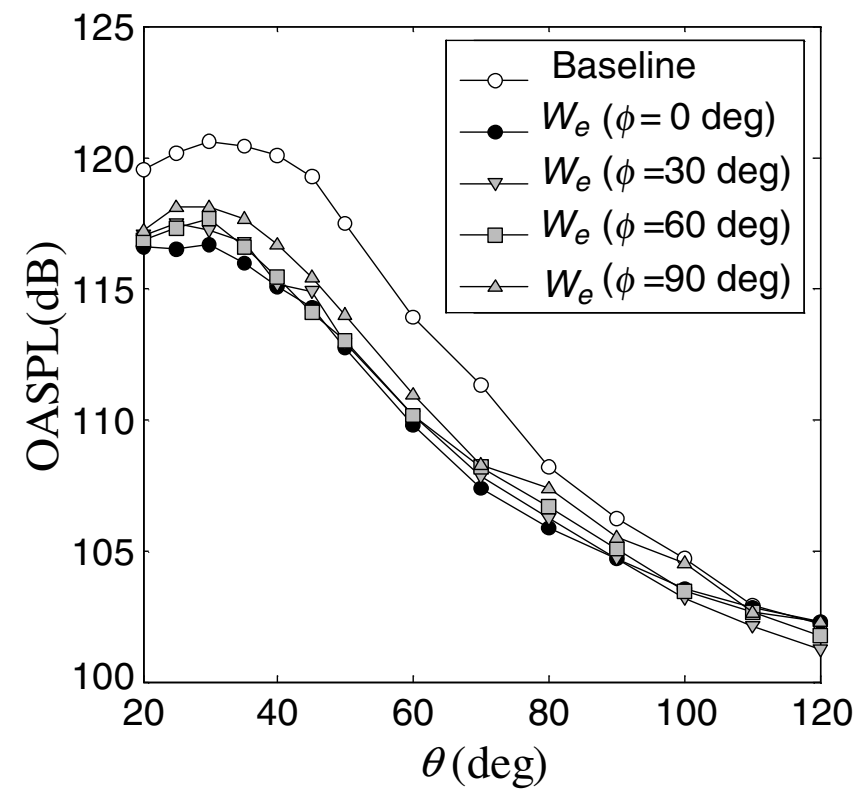

Fig. 14 Directivity of OASPL for case $W_{e}$ at various microphone azimuth angles.

concentrated near this region [19]. Accordingly, we examine the mean velocity on the plane $x=L_{p}$ to identify basic trends created by the fan flow deflectors. Figure 17 plots the isocontours of $u / U_{p}$ on $x=L_{p}$ for the three cases investigated. Contour levels range from 0.1 (outer) to 0.9 in increments of 0.05 . The contours of the baseline are near-perfect circles indicating good alignment of the three nozzle

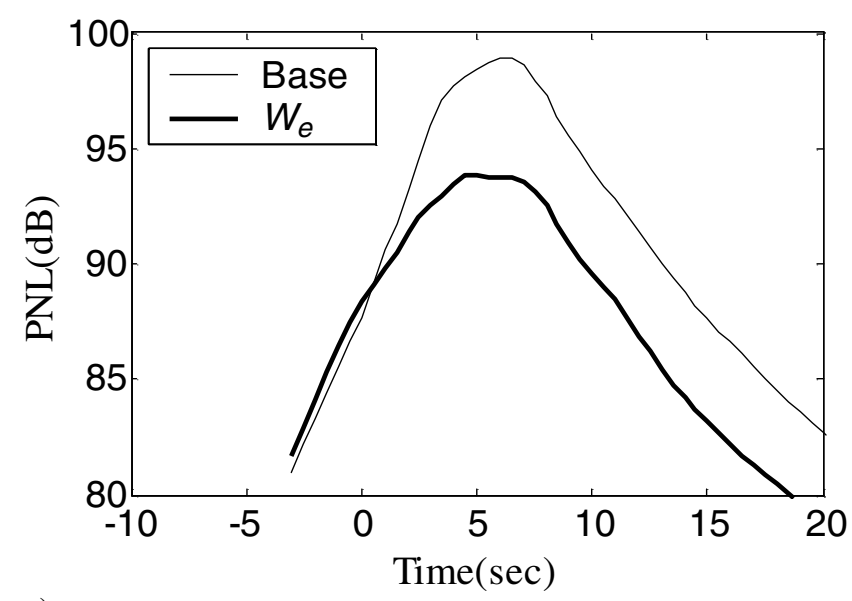

a)

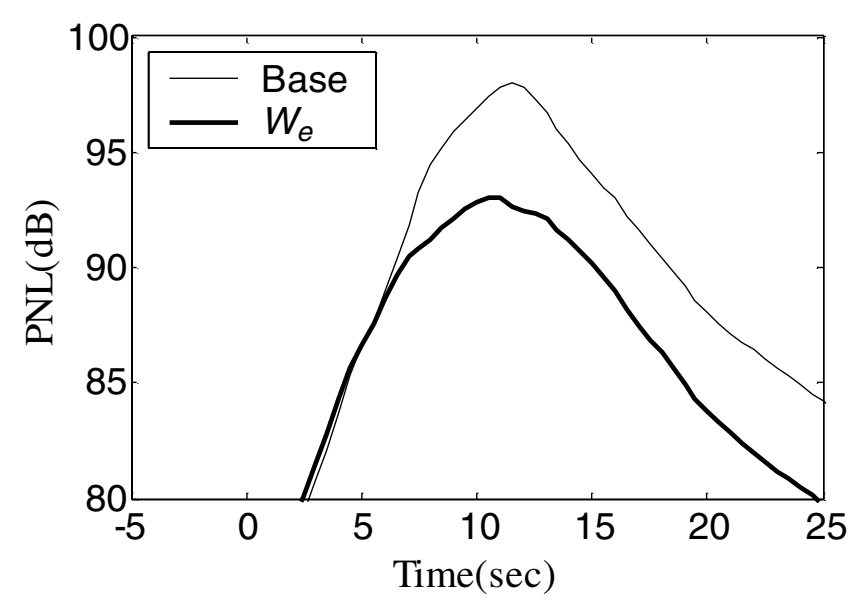

b)

Fig. 15 PNL history for case $W_{e}$ : a) flyover; b) sideline at maximum EPNL. 


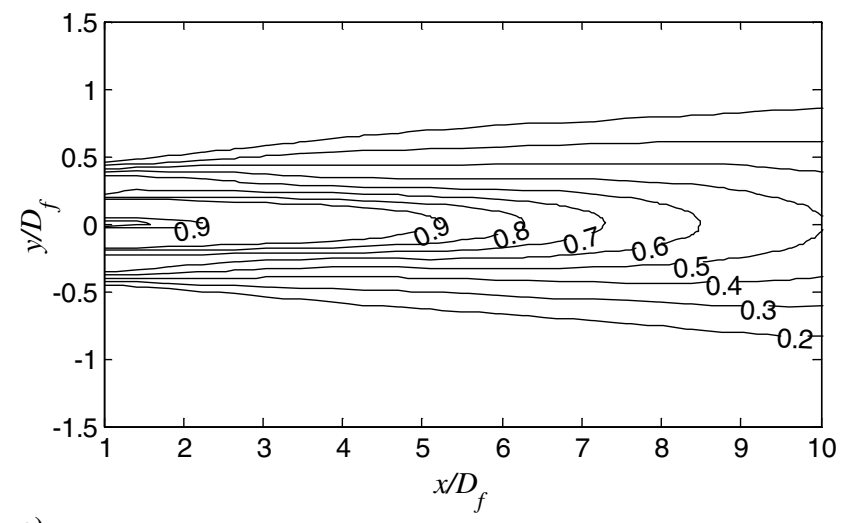

a)

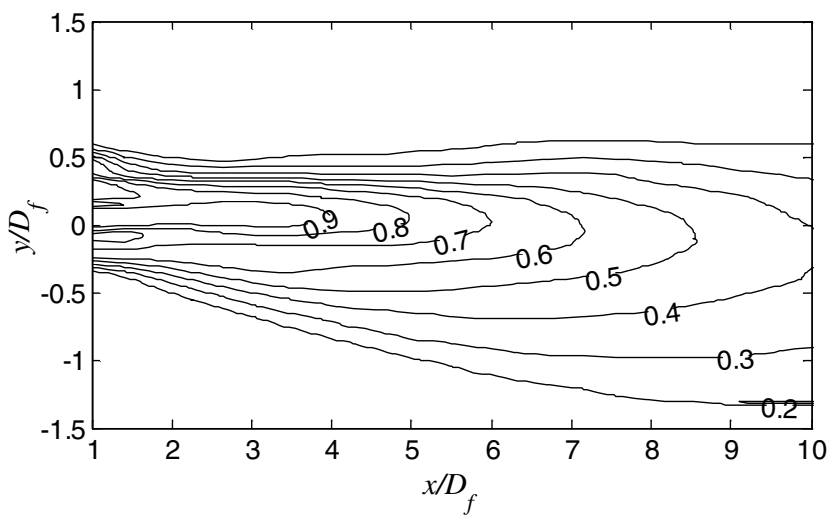

b)

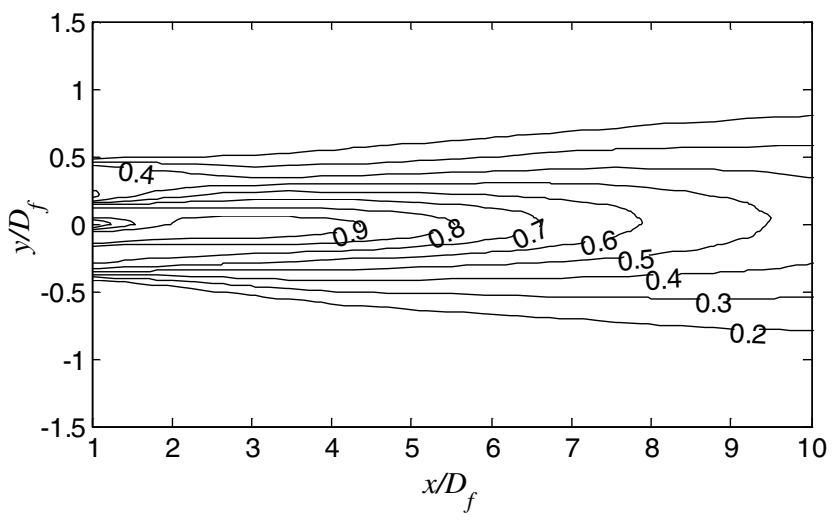

c)

Fig. 16 Isocontours of $u(x, y, 0) / U_{p}$ for a) base, b) $4 \mathrm{~V}$, and c) $W_{e}$.

components (fan duct, core duct, and plug). The contours for jet $4 \mathrm{~V}$ are highly distorted downward with little sideward deflection, consistent with the azimuthal placement of the vanes shown in Fig. 3 and their relatively high angles of attack. On the other hand, the contours of jet $W_{e}$ are distorted moderately, and the deflection is fairly uniform for $-90<\phi<90 \mathrm{deg}$.

If we were to hypothesize that thickening of the lower-speed region of the jet causes noise reduction in the direction of the thickening, the appearance of the contours of Fig. 17 would suggest that jet $4 \mathrm{~V}$ is very quiet downwards but not sidewards and that jet $W_{e}$ is moderately quiet both downwards and sidewards. This hypothesis, though simplistic, does correlate with the OASPL results of Figs. 11 and 14. There are important details, however, that must be added to this picture for a more complete acoustic assessment. Case $4 \mathrm{~V}$ indeed was dramatically quieter in the downward direction of peak emission but caused some noise excess in the lateral direction. On the other hand, case $W_{e}$ caused a moderate downward reduction that was spread over a larger range of polar angles. This rendered the downward EPNL benefit of $W_{e}$ practically the same as that of $4 \mathrm{~V}$. In the sideward direction $(\phi>0 \mathrm{deg})$, case $W_{e}$ again provided a benefit over a larger range of polar angles, and this benefit persisted all the

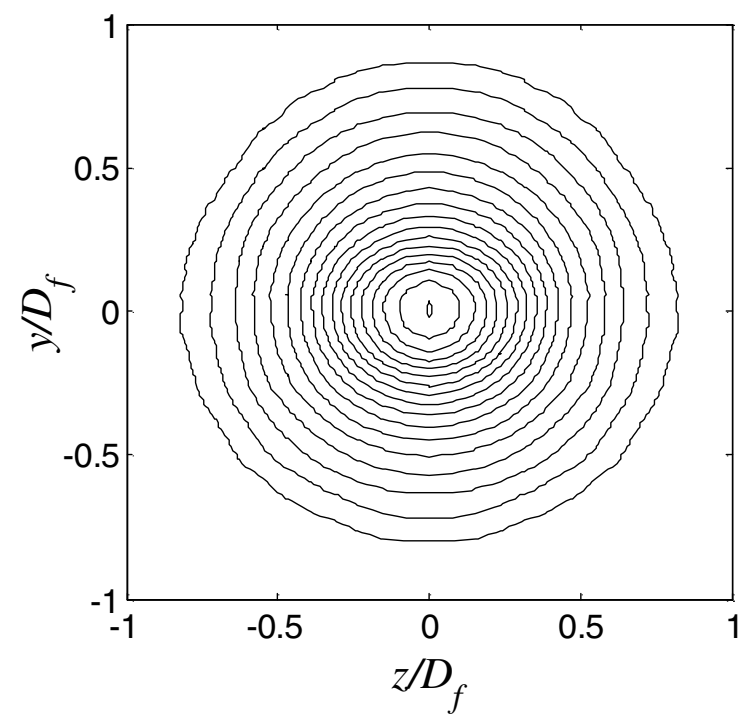

a)

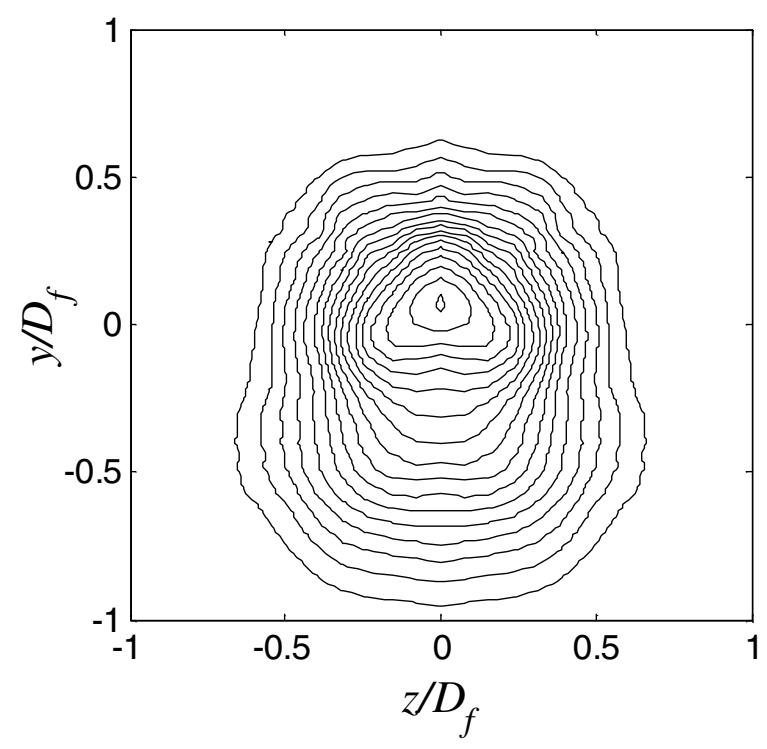

b)

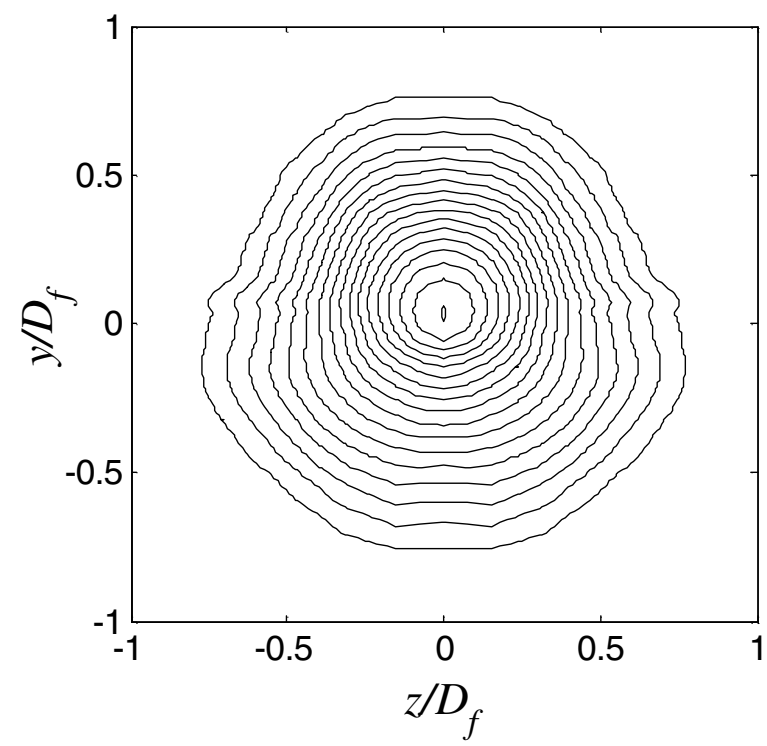

c)

Fig. 17 Isocontours of $u\left(L_{p}, y, z\right) / U_{p}$ for a) base, b) $4 \mathrm{~V}$, and c) $W_{e}$. 


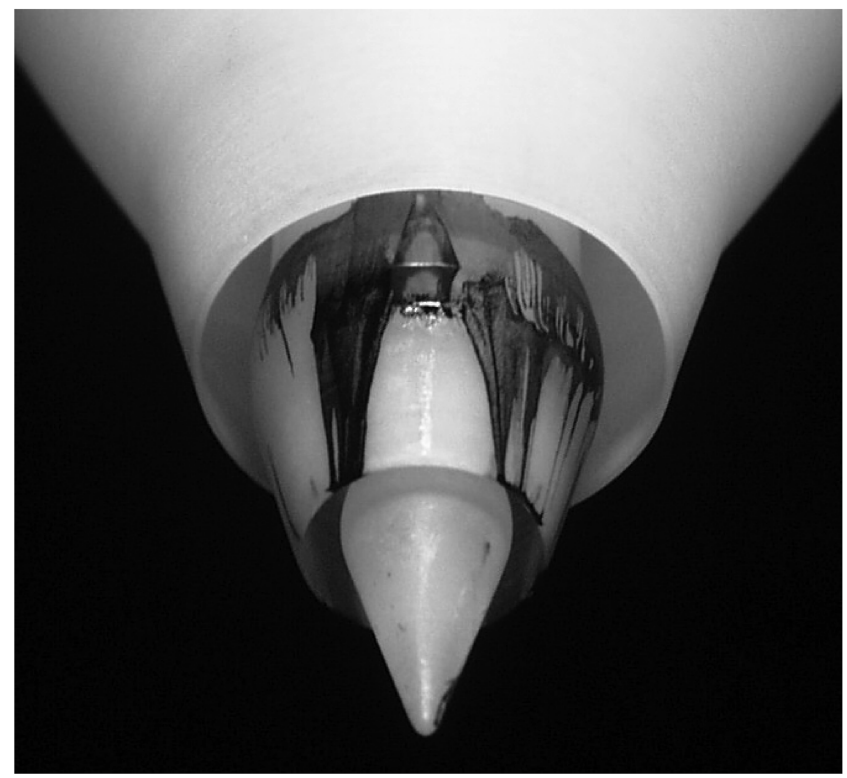

Fig. 18 Surface visualization of flow around the wedge.

way to $\phi=90 \mathrm{deg}$. The connection between the acoustic field and the mean-flow field presented here is very preliminary and will be followed up by a rigorous analysis of the mean velocity distribution, including inflectional layers [5] and radial gradients. Perhaps one lesson that can be drawn at this point is that moderate deflections are preferable to large deflections. This would also make sense from the standpoint of aerodynamic efficiency.

The aerodynamics of the wedge-shaped deflector are unique and need to be studied carefully. A surface flow visualization using ink, shown in Fig. 18, shows that the streaklines from the base of the wedge do not close in the vicinity of the wedge, supporting the evidence from the velocity contours (Fig. 16c) that this wedge produces a long recirculation region. The primary difference from the classic, fully immersed wedge problem is that the top side and base of the wedge are exposed to the ambient (in our case stagnant) air. Therefore, on the free surface of the jet stream flowing around the wedge, the pressure must be ambient. Also, the back pressure is expected to be close to the ambient value. Another important aspect of the wedge deflector is that its ability to push flow downward depends on the shape of the baseline nozzle [20]. In the 3BB-type nozzle the flow lines past the fan exit are convergent, thus imparting a downward movement of flow deflected by the wedge. If the nozzle lines are parallel at the exit, the wedge pushes flow in the sideward $\phi=90$ deg direction only, in which case no downward noise reduction is expected.

\section{Conclusions}

Subscale tests at exhaust conditions and nozzle configurations corresponding to high-bypass separate-flow turbofan engines indicate that fan flow deflection is an effective method for reducing turbulent mixing noise. Two types of deflectors were tested: one comprising two pairs of vanes internal to the fan duct and the other consisting of a wedge positioned outside the fan duct. The noise reduction achieved with the vane-type deflector was strong in the downward direction and moderate in the sideline direction. The wedge-type deflector generated significant noise attenuation in both the downward and sideline directions. The above trends are consistent with the deformation of the mean velocity field. The vanes deflected the fan flow mostly downward and generated a thick lowspeed layer that was confined to the underside of the jet. In contrast, the wedge caused more moderate deflections over roughly an $180 \mathrm{deg}$ arc enveloping the lower half of the jet. The results are particular to the geometry of the deflectors and nozzle tested here. However, they provide guidance over what the desirable deformation of the mean velocity field is to achieve optimal noise suppression. It is important to note that the present study examined the effect of fan flow deflectors on jet mixing noise alone. The deflectors, particularly the internal vanes, could also impact rearward propagating fan noise in ways that remain to be studied.

\section{Acknowledgments}

The support of NASA Glenn Research Center is gratefully acknowledged (Grant NAG-3-2345 monitored by Khairul B. Zaman and James Bridges). J. Bridges is especially thanked for providing us with the NATR nozzle coordinates. Graduate students Kimberley Nishi and Rebecca Shupe performed the acoustic and mean-flow surveys, respectively. The method and system of noise suppression via deflection of the bypass and/or core streams is proprietary to the University of California; U.S. Patent Pending.

\section{References}

[1] Papamoschou, D., and Debiasi, M., "Directional Suppression of Noise from a High-Speed Jet,” AIAA Journal, Vol. 39, No. 3, 2001, pp. 380 387.

[2] Zaman, K. B. M. Q., "Noise- and Flow-Field of Jets from an Eccentric Coannular Nozzle," AIAA Paper 2004-0005, Jan. 2004.

[3] Harper-Bourne, M., "Physics of Jet Noise Suppression," Proceedings of Jet Noise Workshop, CP 2001-211152, NASA, Nov. 2001.

[4] Papamoschou, D., "Engine Cycle and Exhaust Configurations for Quiet Supersonic Propulsion," Journal of Propulsion and Power, Vol. 20, No. 2, 2004, pp. 255-262.

[5] Papamoschou, D., "New Method for Jet Noise Suppression in Turbofan Engines," AIAA Journal, Vol. 42, No. 11, 2004, pp. 2245-2253.

[6] Tam, C. K. W., "Jet Noise: Since 1952," Theoretical and Computational Fluid Dynamics, Vol. 10, Nos. 1-4, Jan. 1998, pp. 393-405.

[7] Saiyed, N. H., Mikkelsen, K. L., and Bridges, J. E., "Acoustics and Thrust of Separate-Flow High-Bypass-Ratio Engines," AIAA Journal, Vol. 41, No. 3, 2003, pp. 372-378.

[8] Doty, M. J., and McLaughlin, D. K., "Acoustic and Mean Flow Measurements of High-Speed, Helium-Air Jets," International Journal of Aeroacoustics, Vol. 2, Nos. 3-4, 2003, pp. 293-333.

[9] Murayama, T., Papamoschou, D., and Liu, F., "Aerodynamics of Fan Flow Deflectors for Jet Noise Suppression,” AIAA Paper 2005-0994, Jan. 2005.

[10] Papamoschou, D., "Acoustic Simulation of Hot Coaxial Jets using Cold Helium-Air Mixture Jets," AIAA Paper 2005-0208, Jan. 2005; also Journal of Propulsion and Power (to be published).

[11] Tam, C. K. W., "Influence of Nozzle Geometry on the Noise of HighSpeed Jets," AIAA Journal, Vol. 36, No. 8, 1998, pp. 1396-1400.

[12] Savitzky, A., and Golay, M. J. E., "Smoothing and Differentiation of Data by Simplified Least Squares Procesures," Analytical Chemistry, Vol. 36, No. 8, 1964, p. 1627.

[13] McGowan, R. S., and Larson, R. S., "Relationship Between Static, Flight and Simulated Flight Jet Noise Measurements," AIAA Journal, Vol. 22, No. 4, 1984, pp. 460-464.

[14] Murakami, E., and Papamoschou, D., "Eddy Convection in Supersonic Coaxial Jets," AIAA Journal, Vol. 38, No. 4, 2000, pp. 628-635.

[15] Bass, H. E., Sutherland, L. C., Zuckerwar, A. J., Blackstock, D. T., and Hester, D. M., "Atmospheric Absorption of Sound: Further Developments," Journal of the Acoustical Society of America, Vol. 97, No. 1, 1995, pp. 680-683.

[16] Noise Standards: Aircraft Type and Airworthiness Certificiation, Federal Aviation Regulations Federal Aviation Administration, Jan. 2001, Pt. 36.

[17] Society of Automotive Engineers Aerospace A21 Committee, "Prediction of Lateral Attenuation of Airplane Noise During Takeoff and Landing," Society of Automotive Engineers Information Report SAE AIR-1751, Mar. 1981.

[18] Tanner, M., Determination of Base Drag with Application to the Near Wake of Wedges, Nr. 31, Mitteilungen aus dem Max-Planck Institut für Strömungsforschung und der Aerodynamischen Versuchsanstalt, MaxPlanck Institut, Göttingen, 1964.

[19] Narayanan, S., Barber, T. J., and Polak, D. R., "High Subsonic Jet Experiments: Turbulence and Noise Generation Studies," AIAA Journal, Vol. 40, No. 3, 2002, pp. 430-437.

[20] Zaman, K. B. M. Q., and Papamoschou, D., "Effect of a Wedge on Coannular Jet Noise," AIAA Paper 2006-0007, Jan. 2006. 